\title{
Pseudo Papillary and Solid Pancreatic Tumor (PPSPT): A Diagnosis Not to Miss in Child
}

\author{
Hana Elmansouri ${ }^{1}$, Kenza Elatiqii ${ }^{1}$, Sara Dehbi ${ }^{1}$, Salma Amouzoune ${ }^{2}$, Hanane Rais ${ }^{2}$, \\ Ibtissam Zouita ${ }^{1}$, Dounia Basraoui ${ }^{1}$, Hicham Jalal ${ }^{1}$ \\ ${ }^{1}$ Department of Radiology of Mother and Child Hospital, Med VI University Hospital, Marrakesh, Morocco \\ ${ }^{2}$ Department of Anatomic Pathology, Med VI University Hospital, Marrakesh, Morocco \\ Email: hana.elmansouri@gmail.com
}

How to cite this paper: Elmansouri, H., Elatiqi, K., Dehbi, S., Amouzoune, S., Rais, H., Zouita, I., Basraoui, D. and Jalal, H. (2019) Pseudo Papillary and Solid Pancreatic Tumor (PPSPT): A Diagnosis Not to Miss in Child. Open Access Library Journal, 6: e5343.

https://doi.org/10.4236/oalib.1105343

Received: March 18, 2019

Accepted: May 5, 2019

Published: May 8, 2019

Copyright $\odot 2019$ by author(s) and Open Access Library Inc.

This work is licensed under the Creative Commons Attribution International License (CC BY 4.0).

http://creativecommons.org/licenses/by/4.0/

\section{(c) (i) Open Access}

\begin{abstract}
Pseudo papillary and solid pancreatic tumor (PPSPT) is a rare tumor that occurs almost exclusively in adolescents and young women. Radiological exploration is mainly based on ultrasound and CT, which can often guide the diagnosis. We report the case of a 12-year-old girl, who was referred for suspicion of a hydatid cyst of the liver. Abdominal ultrasound showed a large solid-cystic mass, in contact with the hepatic hilum. Abdominal CT allowed a better study of the localization and the anatomical relationships of the mass. It was pancreatic head tumor encasing the portal vein and compressing the common biliary duct. The CT features suggest more a PPSPT or a pancreatoblastoma. The pathological study after surgery confirmed the diagnosis of PPSPT.
\end{abstract}

\section{Subject Areas}

Radiology \& Medical Imaging

\section{Keywords}

Solid Pseudopapillary Tumor, Pancreas, Imaging

\section{Introduction}

Pseudo papillary and solid pancreatic tumor (PPSPT) is a rare tumor that occurs almost exclusively in adolescents and young women [1]. Radiological exploration is mainly based on ultrasound and CT, which can often guide the diagnosis [2] [3]. The aim of this study is to analyze the clinicopathological and radiological characteristics of solid pseudopapillary tumor in children.

\section{Case Presentation}

The patient is 12-year-old child with a history of exposure to dogs as well as an 
aunt treated for hepatic hydatid cyst; which presented with a right hypochondrium pain. The physical examination was almost normal. She was referred to university hospital for a suspicion of hepatic type IV hydatid cyst after performing an abdominal ultrasound (Figure 1). The abdominal CT revealed a well-circumscribed solido cystic mass of the pancreatic head measuring $8 \times 10$ $\mathrm{cm}$. It was hypodense, heterogeneous with spontaneously hyperdense hemorrhagic zones (Figure 2(a) and Figure 2(b)). This mass encased the portal trunk and compresses the common bile duct with dilatation of intra hepatic ducts. Ultrasound and CT features (Figure 1 and Figure 2) did not correspond to an hepatic hydatid cyst. The two diagnoses suggested were a PPSPT or a pancreatoblastoma. The treatment was a cephalic duodeno-pancreatectomy with portal resection. The histopathological and immunohistochemical study was consistent with SPT of the pancreas.

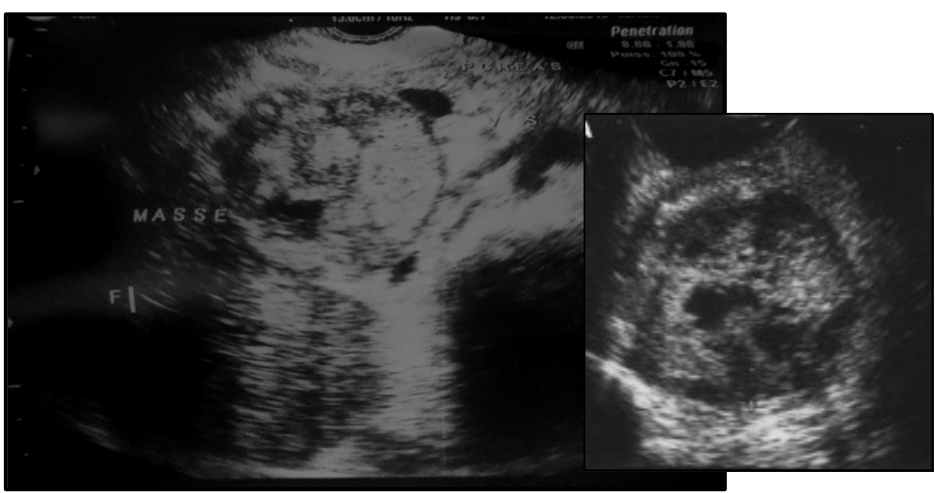

Figure 1. Ultrasound imaging showing heterogeneous mass next to the hepatic hilum, well defined with solid and cystic component.

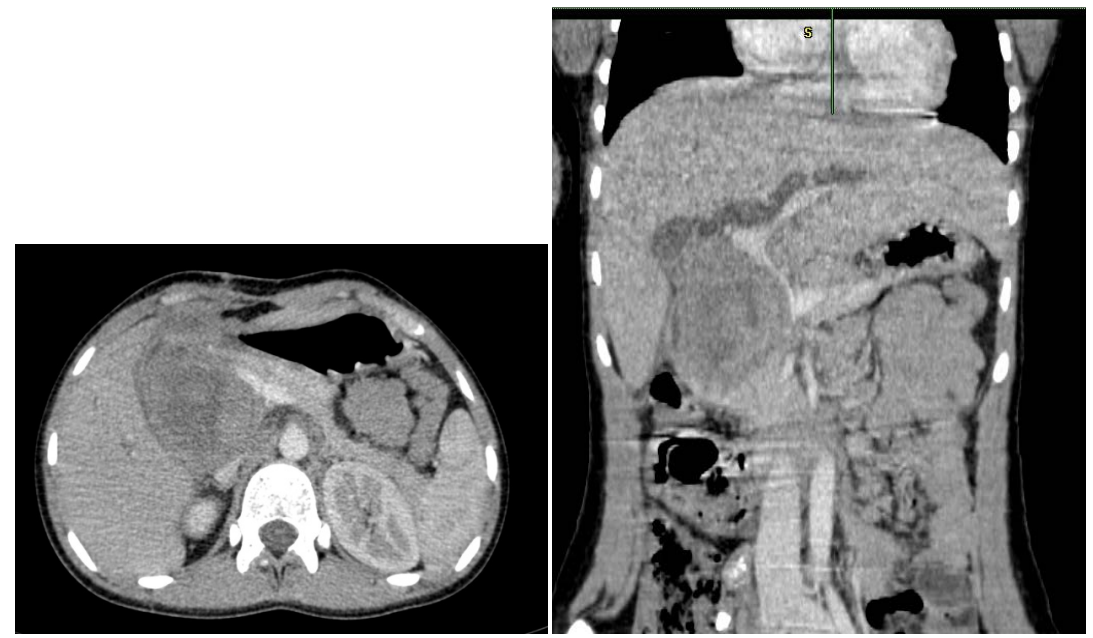

(a)

(b)

Figure 2. Axial (a) and coronal (b) contrast-enhanced CT images demonstrate a large mass in the head of the pancreas (arrow). It is well-defined with a pseudocapsule. It is predominantly solid with central cystic components and areas of hemorrhagic changes. The mass encases the portal trunk and compress the common bile duct with dilatation of intra hepatic ducts. 


\section{Discussion}

The papillary and solid pancreatic tumor is a rare tumor that accounts for $1 \%$ to $2 \%$ of exocrine tumors [4], and $52 \%$ to $71 \%$ of pancreatic tumors in children [5]. It mostly affects females (95\% of cases) and is often discovered at an age ranged between 20 and 30 years old [1].

This tumor is mainly located in the body or the tail of the pancreas [6]. In our patient, the tumor was cephalic. It may develop outside the pancreatic gland (retroperitoneum, duodenum, mesocolon, liver) [7] with a pathogenesis that remains poorly known. The clinical picture is nonspecific. It is usually discovered during abdominal pain or a palpable mass in children, but rarely after signs of digestive or biliary compression [8] [9]. The radiological diagnosis is mainly based on abdominal ultrasonography and CT [2] [3]. Plain abdominal radiography is not commonly performed and may reveal peripheral or motte micro calcifications [3].

Ultrasound often shows a heterogeneous echogenic lesion with cystic and solid areas [2] [3].

The peripheral capsule is rarely visualized. Abdominal computed tomography shows a hypodense, heterogeneous lesion with spontaneously hyperdense zones which correspond to the hemorrhagic degeneration. Calcifications are detected in $29 \%$ of cases. After contrast injection, the lesion is weakly and heterogeneously enhanced in the center. The later enhancement of its fibrous capsule is also detected [2] [3]. MR imaging typically demonstrates a well-defined lesion with heterogeneous signal intensity on T1- and T2-weighted images without a fatty signal within the lesion. It is surrounded by a capsule often hypointense T1 with late gadolinium enhancement [3].

Local invasion has been reported in $15 \%$ of cases [9]. Secondary localizations have been reported in $5 \%$ of the cases, which mainly affect the liver.

The radiological polymorphism of this tumor makes the diagnosis difficult. The differential diagnoses in children include mainly pancreatoblastoma [2], dermoid cyst, lymphoma and pseudocystic lesions of the pancreas [10]. In our context, The hydatid cyst of the pancreas in its pseudo-tumoral form remains also as a differential diagnosis of PPSTP. In our patient, the history of exposure to dogs and hydatid cyst in the aunt, had impacted the initial clinical reasoning.

The positive diagnosis of this tumor remains pathological. Some authors suggest carrying out a percutaneous biopsy under radiological control. It enables the obtention of a preoperative diagnosis in more than $80 \%$ of cases [11]. But the risk of tumor dissemination remains significant [2]. In the majority of cases, the immunohistochemical study is required for the diagnosis of these tumors. The treatment is mainly based on surgical resection. It ranges from simple enucleation to a total pancreatectomy depending on the tumor topography and local invasion [4].

\section{Conclusion}

Despite the fact that the pseudo papillary and solid tumor of the pancreas is rare, 
the radiologist should be aware of this disease and their radiological features in the child and the young teenager.

\section{Contributions of the Authors}

All the authors assisted to this work according to the criteria of the ICMJE.

\section{Conflicts of Interest}

The authors declare no conflicts of interest regarding the publication of this paper.

\section{References}

[1] De Calan, L., Le Bodic, M.F. and Vilgrain, V. (1997) Les tumeurs pseudo-papillaires et solides. Monographies de l'Association française de chirurgie, Arnette Ed., 111-117.

[2] Danon, O., Mofredj, A., Morsli, F., Arnould, M.D., Pariente, D. and Waguet, J. (2000) Tumeur papillaire solide du pancréas chez un enfant. Annales de Medecine Interne, 151, 606-608.

[3] Cantisani, V., Mortele, K.J., Glickman, J.N., Ricci, P., Passariello, R. and Ros, P.R. (2003) MR Imaging Features of Solid Pseudopapillary Tumor of the Pancreas in Adults and Pediatric Patients. American Journal of Roentgenology, 181, 395-401. https://doi.org/10.2214/ajr.181.2.1810395

[4] Yagci, A., Yakan, S., Coskun, A., Ergan, N., Yildirim, M., Yalcin, E., et al. (2013) Diagnosis and Treatment of Solid Pseudopapillary Tumor of the Pancreas: Experience of One Single Institution from Turkey. World Journal of Surgical Oncology, 11, 308. https://doi.org/10.1186/1477-7819-11-308

[5] Ahmed, T.S., Chavhan, G.B., Navarro, O.M. and Traubici, J. (2013) Imaging Features of Pancreatic Tumors in Children: 13-Year Experience at a Pediatric Tertiary Hospital. Pediatric Radiology, 43, 1435-1443. https://doi.org/10.1007/s00247-013-2721-2

[6] Notohara, K., Hamazaki, S., Tsukayama, C., Nakamoto, S., Kawa-Bata, K., Mizobuchi, K., et al. (2000) Solid-Pseudopapillary Tumor of the Pancreas. The American Journal of Surgical Pathology, 24, 1361-1371. https://doi.org/10.1097/00000478-200010000-00005

[7] Podevin, J., Triau, S., Mirallie, E. and Le Borgne, J. (2003) Tumeurs pseudopapillaires et solides du pancréas: À propos de cinq cas et revue de la littérature. Annales de Chirurgie, 128, 543-548. https://doi.org/10.1016/S0003-3944(03)00214-1

[8] Huang, H.L., Shih, S.C., Chang, W.H., Wang, T.E., Chen, M.J. and Chan, Y.J. (2005) Solid Pseudopapillary Tumor of the Pancreas: Clinical Experience and Literature Review. World Journal of Gastroenterology, 11, 1403-1409. https://doi.org/10.3748/wjg.v11.i9.1403

[9] Abid, M., Ben Salah, K., Guirat, M.A., Cheikhrouhou, H., Khlif, M., Khabir, A., et al. (2009) Tumeurs pseudopapillaires et solides du pancréas: Deux observations et revue de la littérature. La Revue de Médecine Interne, 30, 440-442. https://doi.org/10.1016/j.revmed.2008.10.013

[10] Edirimanne, S. and Connor, S.J. (2008) Incidental Pancreatic Cystic Lesions. World Journal of Surgery, 32, 2028-2037. https://doi.org/10.1007/s00268-008-9633-6

[11] Guedira, M., Hrora, A., Raïss, M., El Alaoui, M., Kettani, F. and Tounsi, A. (2006) Tumeurs pseudopapillaires et solides du pancréas. Journal de Chirurgie, 143, 271-273. https://doi.org/10.1016/S0021-7697(06)73690-0 